Использование возможностей социальных сетей и мобильных устройств для защиты адвокатами прав и законных интересов подозреваемых (обвиняемых) и выявления прокурорами нарушений по уголовным делам

\begin{abstract}
Аннотация. Процесс развития общественных отношений и перехода к информационному обществу затрагивает и уголовно-процессуальную сферу. Стороны защиты и обвинения начинают использовать возможности сферы высоких технологий для доказывания по уголовным делам, выявления нарушений, защиты прав участников уголовного процесса. Эффективное использование указанных возможностей повышает результативность процессуальной деятельности того или иного участника. Автор приходит к выводу, что проверка законности производства, версии обвинения либо защиты в современных условиях происходит гораздо быстрее, чем это было раньше. В статье идет речь об использовании социальных сетей и мобильных устройств прокурорами для выявления нарушений по уголовным делам, а адвокатами в защите прав и законных интересов подзащитных. Автором изучаются два актуальных направления использования сферы высоких технологий по уголовным делам - это анализ содержимого социальных сетей и связей между зарегистрированными в них лицами, а также определение местоположения лица, телефона, автомобиля либо иного объекта. В заключение статьи подготовлены рекомендации прокурорам, оперативным сотрудникам и адвокатам по использованию социальных сетей и мобильных устройств в их деятельности.

Ключевые слова: выявление фальсификации прокурором; фальсификация материалов оперативно-розыскной деятельности; ходатайства адвоката; ходатайства подозреваемого (обвиняемого); определение местоположения; социальные сети; доказательства; сфера высоких технологий; материалы оперативно-розыскной деятельности; получение информации об абонентах и (или) абонентских устройствах; следственные действия; понятые; доказательства.

Для цитирования: Хайдаров А. А. Использование возможностей социальных сетей и мобильных устройств для защиты адвокатами прав и законных интересов подозреваемых (обвиняемых) и выявления прокурорами нарушений по уголовным делам // Актуальные проблемы российского права. - 2020. - Т. 15. - № 5. C. 179-187. - DOI: 10.17803/1994-1471.2020.114.5.179-187.
\end{abstract}

(C) Хайдаров А. А., 2020

* Хайдаров Альберт Анварович, кандидат юридических наук, профессор кафедры прокурорского надзора за исполнением законов оперативно-розыскной деятельности и участия прокурора в уголовном судопроизводстве Казанского юридического института (филиала) Университета прокуратуры Российской Федерации

Московская ул., д. 41, г. Казань, Республика Татарстан, Россия, 420111

skywriter_al@mail.ru 


\title{
The Use of Social Networks and Mobile Devices Capabilities for the Protection of Lawyers' Rights and Legitimate Interests of Suspects (Accused) and Identification of Violations in Criminal Cases by Prosecutors
}

\author{
Albert A. Khaydarov, Cand. Sci. (Law), Professor of the Department of Prosecutorial Supervision \\ over the Execution of Investigative Activities Laws and the Participation of the Prosecutor in the \\ Criminal Procedure, Kazan Law Institute (Branch), University of the Prosecutor's Office of the \\ Russian Federation \\ ul. Moskovskaya, d. 41, Kazan, Republic of Tatarstan, Russia, 420111 \\ skywriter_al@mail.ru
}

\begin{abstract}
The process of developing public relations and the transition to the information society has also affected the criminal procedure sphere. The defense and prosecution are starting to use the capabilities of the high-tech sphere to prove violations in criminal cases, protect the rights of participants in criminal proceedings. The effective use of these opportunities increases the effectiveness of the procedural activities of a particular participant. The author concludes that the verification of the lawfulness of the proceedings, the version of the prosecution or the defense in modern conditions is much faster than it used to be. The paper covers the use of social networks and mobile devices for prosecutors to identify violations in criminal cases, and for lawyers to protect the rights and legitimate interests of defendants. The author studies two topical areas of using the high-tech sphere in criminal matters. This is the analysis of the contents of social networks and the relationships between the persons registered in them, as well as finding the location of a person, phone, car or other object. In conclusion, the paper provides recommendations to prosecutors, operational officers and lawyers on the use of social networks and mobile devices in their activities.

Keywords: detection of fabrication by the prosecutor; falsification of materials of operational investigative activities; petitions of a lawyer; petitions of the suspect (accused); location finding; social networks; proof; sphere of high technologies; materials of operational investigative activities; receiving information about subscribers and (or) subscriber devices; investigative procedure; witnesses; evidence.

Cite as: Khaydarov AA. Ispolzovanie vozmozhnostey sotsialnykh setey i mobilnykh ustroystv dlya zashchity advokatami prav i zakonnykh interesov podozrevaemykh (obvinyaemykh) i vyyavleniya prokurorami narusheniy po ugolovnym delam [The Use of Social Networks and Mobile Devices Capabilities for the Protection of Lawyers' Rights and Legitimate Interests of Suspects (Accused) and Identification of Violations in Criminal Cases by Prosecutors]. Aktualnye problemy rossiyskogo prava. 2020;15(5):179-187. DOI: 10.17803/1994-1471.2020.114.5.179-187. (In Russ., abstract in Eng.).
\end{abstract}

$\mathrm{P}$ азвитие сферы высоких технологий находит отражение в правоприменительной практике при расследовании уголовных дел и надзоре за законностью производства предварительного расследования ${ }^{1}$. Возможностями указанной сферы пользуются следователи для раскрытия преступлений и доказывания противоправной деятельности преступников, прокуроры для выявления нарушений процессуальной деятельности поднадзорных органов, а также адвокаты для защиты подозреваемых (обвиняемых) от обвинения.

Одним из актуальных способов защиты прав и законных интересов подозреваемых (обвиняемых) адвокатами и выявления прокурорами нарушений в материалах оперативно-розыск-

1 Таболина К. А. Об оптимизации надзора прокурора в досудебном производстве уголовного процесса в условиях развития цифровых технологий // Сб. мат. межд. науч. практ. конф. «Уголовное производство: процессуальная теория и криминалистическая практика». Симферополь: Ариал, [Б. г.]. С. $118-119$; Масленникова Л. Н., Собенин А. А. Регистрация сообщения о преступлении и начало расследования в новой цифровой реальности // Российский следователь. 2019. № 6. С. 12-16 ; Масленникова Л. Н., Таболи- 
ной деятельности и уголовных дел является использование возможностей социальных сетей.

В основе использования этих сетей в установлении тех или иных фактов по уголовным делам лежит процесс идентификации пользователя и анализ содержимого его профиля в социальной сети. Идентификация пользователя в социальных сетях затруднена из-за возможности использования чужих фотографий, анкетных данных и т.д. Все это затрудняет получение необходимой информации. Возможности идентифицировать пользователя есть не только у адвоката и прокурора, но и у следователя (дознавателя). Он может запросить IP-адреса пользователя, установить его, а далее получить доказательства его причастности.

Так, по уголовному делу было установлено и впоследствии осуждено лицо, которое выложило ролик о поджоге административного здания на канал YouTube. В процессе расследования должностными лицами был осуществлен мониторинг сети Интернет на предмет установления лиц, причастных к совершению преступления. Выявив выложенный на сайте YouTube ролик, должностные лица без труда установили IP-адрес лица, его выложившего, а затем были собраны неоспоримые доказательства его причастности к совершенному преступлению.

Сторона защиты по уголовным делам лишь ограниченно может использовать способы идентификации пользователя, действуя в основном через следователя (дознавателя). Кроме этого, адвокат может использовать информацию, полученную из социальных сетей, как ориентирующую, в подтверждение своей защитительной позиции, а потом заявить ходатайство следователю (дознавателю) о производстве соответствующих следственных действий для подтверждения полученной из сети Интернет информации.

По уголовным делам может использоваться следующая информация из профиля социальной сети: год рождения, место рождения, место учебы, перечень друзей пользователей, информация об "общих друзьях» пользователя, информация о местоположении лица в определенный момент времени (check-in) с прикрепленной информацией, размещение фотографий с тем или иным лицом на странице в социальной сети и т.д.

Подобная информация может использоваться прокурором при осуществлении проверок по уголовным делам. Так, у заместителя прокурора при осуществлении надзора возникли подозрения в заинтересованности оперативного сотрудника в исходе определенного уголовного дела. Изучив страницу оперативного сотрудника в социальной сети, прокурор выявил фотографии, на которых были запечатлены оперативный сотрудник с фигурантами того уголовного дела. В дальнейшем оперативник был отстранен от оперативного сопровождения уголовного дела.

Кроме этого, прокурором, следователем (дознавателем) и адвокатом может использоваться информация о телефонных соединениях абонентов, о местоположении мобильного устройства через обращение к базовым станциям, о передвижении лица при наличии у него сотового телефона, а также переписка в социальных сетях или в программах обмена сообщениями (WhatsApp, Viber и т.д.).

Приведем пример, когда стороне защиты удалось добиться прекращения уголовного преследования. Так, подозреваемый по уголовному делу С. эффективно использовал возможности социальных сетей и мобильных устройств для своей защиты от обвинения. Понимание современных интернет-технологий, возможностей изучения содержания профилей участников уголовного процесса в социальных сетях, работы программного обеспечения компьютеров и мобильных устройств, возможностей мобильной связи по установлению местоположения мобильных устройств в определенный период времени и самое важное - умение получить подобную информацию помогло стороне защиты поставить под сомнение законность производства в отноше-

на К. А. Оптимизация надзора прокурора за принятием решений, обеспечивающих доступ к правосудию, в условиях развития цифровых технологий // Законность. 2019. № 7 ; Зуев С. В. Развитие информационных технологий в уголовном судопроизводстве : монография. М. : Юрлитинформ, 2018. 248 с. 
нии С. оперативно-розыскного мероприятия и в целом всех материалов оперативно-розыскной деятельности по двум эпизодам противоправной деятельности.

С. подозревался в совершении преступления, предусмотренного ч. 2 ст. 146 УК РФ, а именно в установке нелицензированного программного обеспечения. Преступление было выявлено оперативно-розыскным путем. Оперативный сотрудник Р. в рамках оперативно-розыскного мероприятия «проверочная закупка» обратилась к С. с просьбой об установке на принадлежащий ей персональный компьютер программного обеспечения (Windows, Office, Компас-3D) за денежное вознаграждение. 27 октября С. установил на компьютер Р. указанные программы. Кроме этого, через 5 дней после указанного оперативно-розыскного мероприятия к оперативному сотруднику Р. обратилась некая А., которая сообщила, что 10 октября на ее компьютер было также установлено программное обеспечение по цене, значительно отличающейся от рыночной стоимости лицензионных продуктов. А. сообщила мобильный телефон, по которому она приглашала мужчину, производившего установку программ, им оказался С.

Получение информации о социальных связях и личной информации об участниках уголовного судопроизводства во все времена использовалось в процессе установления тех или иных фактов по уголовным делам. Без использования современных технологий до сих пор получается информация о связях подозреваемого (обвиняемого) с его подельниками путем анализа ответов на запросы о судимостях, данных о месте отбывания наказания, нахождения подозреваемых в закрытых образовательных организациях и т.д. Процесс установления социальных связей между участниками уголовного судопроизводства всегда использовался сторонами обвинения и защиты. В настоящее время этот процесс стал быстрее и проще за счет развития информационных технологий. Участники уголовного судопроизводства, в том числе следователи, оперативники, понятые, заявители, активно выкладывают личную информацию о себе в социальных сетях, добавляют в «друзья» родственников и знакомых.
Так, подозреваемый С. с помощью анализа содержимого социальных сетей получил информацию, что понятые, участвовавшие в ходе изъятия у А. жесткого диска с установленными программами, знакомы с оперативным сотрудником Р., изымавшим этот диск. Первая понятая М. находилась в друзьях в профиле социальной сети у оперативного сотрудника Р. С помощью социальной сети сторона защиты также установила, что второй понятой оказался С. - родной брат друга оперативника Р. При этом родной брат и друг также находились в друзьях в профиле социальной сети у оперативника Р. Кроме этого, подозреваемый и его адвокат обратили внимание на указанное в протоколе место жительства понятого М. Эти местом оказалось административное здание без жилых помещений, хотя в протоколе была указана квартира с определенным номером. После выявления этой информации стороной защиты и начала проверки информации следователем оперативник Р. удаляет из друзей понятых С. и М. Этот факт также фиксируется стороной защиты.

С помощью находящейся в открытом доступе информации об анкетных данных на странице социальной сети сторона защиты установила, что заявительница А., обратившаяся к оперативному сотруднику Р. по факту установки нелицензированных программ, является студенткой 1-го курса юридического колледжа. Студенткой 1-го курса этого колледжа оказалась и понятая О., участвовавшая при проведении оперативно-розыскного мероприятия «проверочная закупка» по другому эпизоду. Дальнейший анализ страниц социальной сети показал, что и вторая понятая Б. также была студенткой того же самого юридического колледжа.

Понятые О. и Б., участвовавшие в ходе оперативно-розыскного мероприятия, были опрошены по материалу проверки, допрошены в качестве свидетелей, подтвердили свои показания в ходе очной ставки с подозреваемым. Сторона защиты проанализировала три факта, сообщенные понятыми: 1) о том, что понятые были знакомы и являлись подругами до производства оперативно-розыскного мероприятия; 2) к понятым в день проведения оперативно-розыскного мероприятия подходил незнакомый им ранее 
оперативный сотрудник Ш. и просил их пройти для участия в оперативно-розыскном мероприятии; 3) местонахождение понятых, когда из забирал оперативный сотрудник для участия в оперативно-розыскной мероприятии. Сторона защиты заявляет ходатайство о детализации телефонных соединений с данными по базовым станциям мобильных устройств понятых и оперативного сотрудника Ш.

Анализ социальных сетей показал, что понятые О. и Б. в действительности подругами не являются, несмотря на то что они учатся в одном колледже. Они являются студентками разных курсов и в друзьях друг у друга в социальной сети не значатся. Кроме этого, детализация телефонных соединений показала, что оперативный сотрудник заранее созвонился с понятыми О. и Б., потом забрал их вместе из определенного места и отвез к дому, где производилось оперативно-розыскное мероприятие «проверочная закупка». Кроме того, детализация телефонных соединений понятых за несколько месяцев показала, что они друг с другом на протяжении запрошенного периода не созванивались. Эти и другие обстоятельства поставили под сомнение факт знакомства понятых до производства оперативно-розыскного мероприятия. Сторона защиты просила в ходатайстве органы следствия предоставить доказательства знакомства понятых О. и Б. до проведения оперативно-розыскного мероприятия с помощью мессенджеров, переписки из социальных сетей и других способов связи. Кроме этого, были обнаружены противоречия в показаниях понятых и их местоположении в конкретный период времени.

Таким образом, полученные стороной защиты сведения противоречили показаниям сотрудников полиции и понятых, в том числе и тем показаниям, которые были даны на очных ставках с подозреваемым.

Стороной защиты были проанализированы также фотографии на страницах понятых О. и Б. Оказалось, что на странице у Б. размещены фотографии, сделанные в разное время, в форме с официальными нашивками МВД. В последующем стороной защиты было заявлено ходатайство о заинтересованности понятых. После заявления подобных ходатайств и начавшейся проверки указанных фактов страницы обеих понятых также были удалены из сети Интернет.

Мы уже указывали выше, что 1 ноября заявительница А. обратилась к оперативным сотрудникам по факту установки на ее компьютер нелицензированного программного обеспечения. Сторона защита предположила, что понятые О. и Б., так же как и заявительница по другому эпизоду А., были знакомы с оперативными сотрудниками задолго до производства оперативно-розыскного мероприятия. Поэтому сторона защиты заявила ходатайство о детализации звонков А. и оперативного сотрудника Р. на предмет выявления противоречий в их показаниях. Было установлено, что А. звонила оперативному сотруднику Р. за 5 дней до того, как по материалам дела она впервые обратилась к этому сотруднику с сообщением об установке нелицензированного программного обеспечения. Эта дата совпала с днем производства оперативно-розыскного мероприятия «проверочная закупка» по эпизоду С.

Конечно, отдельно взятое противоречие, выявленное стороной защиты с помощью социальных сетей либо с помощью детализации телефонных соединений, вряд ли смогло бы стать основанием для прекращения уголовного преследования. Однако из приведенного примера видно, что стороной защиты была найдена совокупность подобных нарушений. Кроме этого, по уголовному делу были выявлены и другие противоречия, например в ходе производства компьютерной экспертизы установлено, что не совпадают серийные номера жестких дисков, изъятых в ходе оперативно-розыскного мероприятия, с номерами, указанными в материалах оперативно-розыскной деятельности. Именно совокупность выявленных стороной защиты противоречий в материалах дела привела в последующем к прекращению уголовного дела.

В условиях цифровизации современного общества и использования участниками уголовного процесса возможностей в сфере высоких технологий выявление нарушений и противоречий в материалах по уголовным делам становится заметно проще.

Такие способы получения информации, как детализация телефонных соединений, опреде- 
ление местоположения лица с помощью мобильного телефона через оператора связи, получение информации об анкетных данных, о друзьях и других сведений из профиля социальных сетей, обладают синергетическим эффектом, т.е. эффект усиливается при использовании этих способов в совокупности.

Все эти процессы, безусловно, должны учитываться прокурорами в ходе осуществления надзора за законностью производства предварительного расследования; органами предварительного следствия - при проверке материалов, полученных с помощью оперативно-розыскной деятельности; оперативными сотрудниками - при фиксации противоправных действий; стороной защиты - для выявления нарушений прав подозреваемого (обвиняемого) при расследовании уголовного дела.

Другим актуальным направлением использования высоких технологий в доказывании по уголовным делам является получение сведений о местоположении сотового телефона, автомобиля и других объектов в следственно-судебной практике как прокурорами при проверке законности действий должностных лиц и материалов уголовного дела, следователями в целях подтверждения своей обвинительной версии, так и адвокатами в целях защиты своих подопечных от незаконного и необоснованного обвинения.

Об актуальности вопроса об определении местоположения тех или иных лиц свидетельствует, например, тот факт, что в августе 2018 г. вступили в силу положения Федерального закона № 311-Ф3 «О внесении изменений в статью 8 Федерального закона “Об оперативно-розыскной деятельности" » ${ }^{2}$ о геолокации гаджетов пропавших детей. Суть закона заключается в возможности использования геолокационных данных по заявлению родных и на основании постановления одного из руководителей, ведущих оперативно-розыскную деятельность, с обязательным уведомлением суда (судьи) в течение 24 часов $^{3}$.
Определение местоположения абонента и (или) абонентского устройства по уголовным делам осуществляется с помощью такого следственного действия, как получение информации о соединениях между абонентами и (или) абонентскими устройствами (ст. 186.1 УПК РФ), в случае если речь идет о телефоне (планшете).

Приведем другой пример эффективного использования возможностей сферы высоких технологий в доказывании по уголовным делам и выявлении противоречий в материалах уголовного дела.

Так, 20 сентября примерно в 10:45 на контрольном посту полиции города Энска сотрудниками ГИБДД была остановлена автомашина BMW под управлением И., принадлежащая М., который в момент остановки находился на пассажирском сидении. В ходе осмотра транспортного средства из заднего багажника изъято наркотическое средство. Сотрудником полиции был составлен протокол осмотра транспортного средства. В протоколе осмотра было указано, что изъятие наркотических средств, его упаковка и составление указанного протокола происходило 20 сентября в период с 11:10 до 11:50. Кроме этого, в протоколе были указаны двое понятых П. и С., которые в последующем подтвердили в рамках допросов свое участие в указанном следственном действии и время его производства. По факту изъятия наркотических средств на контрольном посту полиции из автомобиля М. следователем было возбуждено уголовное дело по признакам преступления, предусмотренного ч. 2 ст. 228 УК РФ.

Позже М. в ходе допроса в качестве подозреваемого сообщил, что 20 сентября примерено в 11:00 его автомобиль действительно был остановлен сотрудниками ГИБДД на контрольном посту. М. открыл багажник своего автомобиля. Со слов М., при проведении досмотра кроме М. присутствовали И. и два сотрудника ГИБДД. После проведения досмотра багажника автомобиль он закрыл и вместе с сотрудниками

2 СПС «КонсультантПлюс» (дата обращения: 20.09.2019).

3 Козлова Н. Найти за минуты // Российская газета. 16 июля 2018 г. Специальный выпуск № 7615 (153). URL: https://rg.ru/2018/07/16/propavshih-detej-predlozhili-iskat-po-geolokacii-gadzhetov.html (дата обращения: 20.09.2019). 
ГИБДД проследовал в помещение контрольного поста ГИБДД. Через некоторое время сотрудник ГИБДД попросил проследовать к автомобилю М., где в очередной раз попросил предоставить этот автомобиль к досмотру. М. открыл багажник, а сотрудник ГИБДД начал производить фотоснимки багажника на свой сотовый телефон, после чего вновь попросил пройти в помещение контрольного поста. Со слов М., осмотр с участием понятых проводился гораздо позже. К уголовному делу была приобщена видеозапись осмотра с контрольного поста ГИБДД. Было установлено, что в ходе осмотра автомобиля рядом с сотрудниками ГИБДД действительно находятся люди в гражданской одежде. Видеозапись длительностью 7 минут, но даты и времени видеозаписи на картинке нет.

Адвокат заявил ходатайство об истребовании детализации входящих и исходящих звонков с привязкой к базовым станциям на абонентский номер двух понятых С. и П., об истребовании и о приобщении сведений Гидрометцентра о заходе солнца на 20 сентября, о допросе в качестве свидетеля лиц, находившихся в автомобиле понятого С. в момент остановки автомобиля С. на контрольном посту ГИБДД, о допросе в качестве свидетелей лиц, непосредственно управлявших транспортным средством, принадлежащим М., об истребовании сведений у официального дилера BMW, где был приобретен автомобиль, о месте его нахождения 20 сентября в период с 11:00 до 17:00 на основе данных, получаемых с навигационного оборудования и приемника GPS.

Следователем ходатайство было частично удовлетворено. В последующем следователь обратился в суд в целях получения информации об абонентских устройствах понятых С. и П. с привязкой к базовым станциям.

Выяснилось, что в период проведения осмотра транспортного средства 20 сентября в период времени с 11:10 до 11:50 сотовые телефоны, которые находились при понятых С. и П., регистрировались базовыми станциями, расположенными в других городах, на значительном удалении от места осмотра, что исключило возможность участия понятых в этот временно́й промежуток в рамках указанного следственного действия. Уголовное преследование в отношении гр. М было прекращено.

Сторона защиты в данном случае воспользовалась возможностями мобильной связи по установлению местоположения участников уголовного процесса (понятых) в целях опровержения сведений, содержащихся в протоколе осмотра транспортного средства, а именно времени производства процессуального действия. По уголовному делу имелись и другие доказательства, подтверждающие факт более позднего производства осмотра.

Вопрос об установлении местоположении того или иного объекта либо о его передвижении имеет юридическое значение для квалификации действий лица и наличия признаков состава преступления. Прокуроры могут использовать возможности установления местоположения лица в ходе осуществления проверки материалов дела, направленных им с обвинительным актом (заключением).

Приведем такой пример. Заместитель прокурора, получив материалы уголовного дела с обвинительным актом, решил проверить алиби обвиняемого с помощью определения местоположения его телефона с привязкой к базовым станциям. Гражданин обвинялся по четырем эпизодам краж из дачных домиков. В ходе опроса в кабинете прокурора обвиняемый подтвердил, что все четыре эпизода совершил именно он. Однако прокурор все равно вернул уголовное дело дознавателю, поскольку у него были сомнения в виновности этого лица. После выполнения дознавателем указаний прокурора были получены неопровержимые доказательства непричастности обвиняемого по двум эпизодам обвинения. В момент совершения этих двух преступлений обвиняемый находился в другом городе. При повторном опросе прокурора этого лица стало известно, что два сотрудника оперативно-розыскных аппаратов вынудили этого гражданина с применением силы и угроз взять вину на себя. Впоследствии эти два сотрудника уголовного розыска были осуждены.

Советы прокурорам:

- использовать возможности социальных сетей с целью проверки материалов опера- 
тивно-розыскной деятельности и процессуальных действий на предмет законности их производства;

- использовать возможности определения местоположения лиц, автомобилей и других объектов для выявления фальсификаций материалов оперативно-розыскной деятельности и уголовных дел.

Советы оперативным сотрудникам:

- не регистрироваться в социальных сетях. Тем более что идентификацию пользователя сторона защиты может осуществить, используя анализ социальных связей оперативника либо с помощью анализа атрибутов профиля (например, таких анкетных данных, как учащийся вуза, служба в армии, интересы). А в случае наличия профилей в социальных сетях удалить их;

- выполнять все требования закона при подборе понятых;

- тщательно проверить материалы ОРД на предмет их соответствия той информации, которая может быть получена в последующем по уголовному делу о местоположении мобильных устройств участвующих в ОРМ лиц, либо информации из Интернета (социальные сети, твиттер, инстаграм, форсквер и т.д). Не использовать искажение обстоятельств, предшествующих ОРМ, касающихся места и времени встречи с понятыми, маршрутов и времени передвижения к месту проведения ОРМ и т.д.

Советы защитникам:

- ходатайствовать о производстве очной ставки между подозреваемым и понятыми, участвовавшими в ОРМ. В ходе очной ставки выяснить вопросы о знакомстве между понятыми, между понятыми и оперативными сотрудниками до производства ОРМ, уточнить место встречи с оперативным сотрудником;

- ходатайствовать о детализации телефонных соединений между понятыми (заявителями) и оперативными сотрудниками, задействованными в ОРМ;

- мониторинг социальных сетей на предмет выявления факта знакомства понятых (заявителей) напрямую с оперативными сотрудниками либо использование функции социальной сети "друзья друзей», выявление родственных и иных связей понятых и выявленных "друзей» в социальной сети;

- осуществлять поиск и фиксацию общих фотографий либо иных фотографий, подтверждающих факт заинтересованности понятых.

\section{БИБЛИОГРАФИЯ}

1. Зуев С. В. Развитие информационных технологий в уголовном судопроизводстве : монография. - М. : Юрлитинформ, 2018. - 248 с.

2. Масленникова Л. Н., Собенин А. А. Регистрация сообщения о преступлении и начало расследования в новой цифровой реальности // Российский следователь. - 2019. - № 6. - С. 12-16.

3. Масленникова Л. Н., Таболина К. А. Оптимизация надзора прокурора за принятием решений, обеспечивающих доступ к правосудию, в условиях развития цифровых технологий // Законность. - 2019. № 7.

4. Таболина К. А. Об оптимизации надзора прокурора в досудебном производстве уголовного процесса в условиях развития цифровых технологий // Сб. мат. межд. науч. практ. конф. «Уголовное производство: процессуальная теория и криминалистическая практика». - Симферополь : Ариал, [Б. г.]. C. $118-119$. 


\section{REFERENCES (TRANSLITERATION)}

1. Zuev S. V. Razvitie informacionnyx texnologij v ugolovnom sudoproizvodstve : monografiya. - M. : Yurlitinform, 2018. - $248 \mathrm{~s}$.

2. Maslennikova L. N., Sobenin A. A. Registraciya soobshheniya o prestuplenii i nachalo rassledovaniya $v$ novoj cifrovoj realnosti // Rossijskij sledovatel. - 2019. - № 6. - S. 12-16.

3. Maslennikova L. N., Tabolina K. A. Optimizaciya nadzora prokurora za prinyatiem reshenij, obespechivayushhix dostup k pravosudiyu, v usloviyax razvitiya cifrovyx texnologij // Zakonnost. - 2019. - № 7.

4. Tabolina K. A. Ob optimizacii nadzora prokurora v dosudebnom proizvodstve ugolovnogo processa $v$ usloviyax razvitiya cifrovyx texnologij // Sb. mat. mezhd. nauch. prakt. konf. «Ugolovnoe proizvodstvo: processualnaya teoriya i kriminalisticheskaya praktika». - Simferopol : Arial, [B. g.]. - S. 118-119. 